\title{
O PIBID/História na UNEB e as demandas identitárias do tempo presente
}

\section{The PIBID/history at UNEB and the identitary demands of the present time}

\author{
Adriana Silva Teles Boudoux ${ }^{1}$
}

\begin{abstract}
Resumo
O objetivo deste artigo é analisar os subprojetos do Programa Institucional de Bolsas de Iniciação à Docência executados entre 2014 e 2017 pelas Licenciaturas em História da Universidade do Estado da Bahia, no contexto das demandas identitárias do tempo presente. Para tanto, expõe o debate travado nos campos da História do Tempo do Presente e do Ensino de História sobre as relações destes com as demandas sociais. Em seguida, faz uma apresentação dos subprojetos selecionados para estudo, inserindo-os no cenário brasileiro, onde políticas foram sendo adotadas nos últimos quinze anos, em resposta a reivindicações da sociedade, convocando os professores à construção de uma educação assentada no respeito à diferença, na construção de valores democráticos e na defesa dos direitos humanos.
\end{abstract}

Palavras-chave: PIBID; tempo presente; demandas identitárias.

\begin{abstract}
The objective of this article is to analyze the sub-projects of the Institutional Teaching Fellowships Program executed between 2014 and 2017 by the BSc in History of the University of the State of Bahia, in the context of the identity demands of the present time. To this end, it exposes the debate held in the fields of History of the Present Time and History Teaching on their relationship with social demands. It then presents the subprojects selected for study, inserting them into the Brazilian scenario, where policies have been adopted over the last fifteen years in response to society's demands, calling on teachers to build an education based on respect for difference, the construction of democratic values and the defense of human rights.
\end{abstract}

Keywords: PIBID; present time; identitary demands.

\section{Considerações iniciais}

Este texto traz alguns resultados parciais da pesquisa de doutoramento que venho desenvolvendo e que tem como objeto de estudo os subprojetos do Programa Institucional de Bolsas de Iniciação à Docência das Licenciaturas em História da Universidade do Estado da

\footnotetext{
1 Doutoranda do Programa de Pós-graduação em História da Universidade do Estado de Santa Catarina. Pesquisadora do Laboratório de Ensino de História, LEH, sob a coordenação da professora doutora Cristiani Bereta da Silva, UDESC, e do grupo de pesquisa interinstitucional Oficinas de História, coordenado pela professora Helenice Aparecida Bastos Rocha, UERJ. É docente da Universidade do Estado da Bahia, onde foi coordenadora de área do Programa Institucional de Bolsas de Iniciação à Docência, CAPES, do curso de História do Campus XIV, de 2014 a 2017. E-mail: adrianaboudoux@yahoo.com.br.
} 
Bahia. O objetivo é analisar as relações entre as experiencias formativas de iniciação à docência e as demandas identitárias do tempo presente.

O PIBID se constitui como um dos maiores programas de formação de professores desenvolvidos pelo governo federal através do Ministério da Educação e Cultura, MEC, e da Coordenação de Aperfeiçoamento de Pessoal de Nível Superior, Capes, em parceria com as Instituições de Ensino Superior do Brasil. Foi criado em 2007, integrando as ações do Plano Nacional de Desenvolvimento da Educação, e regulamentado em 2009, completando em 2019 dez anos de sua institucionalização. Tendo como objetivo primordial a valorização da formação docente, por meio da conjugação entre ensino e pesquisa e do diálogo entre universidades e escolas, chegou a contar com cerca de 90 mil participantes em todo o país no ano de 2014 (GATTI e outras, 2014). Consiste na distribuição de bolsas entre licenciandos, bolsistas de iniciação à docência, professores das instituições de ensino superior, coordenadores de área, bem como entre docentes das instituições escolares parceiras, professores supervisores. Os primeiros, geralmente um ou dois proponentes vinculados a uma licenciatura, produzem e submetem um subprojeto que, sendo aprovado, selecionam os demais participantes. Cada universidade envia para apreciação da Capes um projeto institucional que abarca os diversos subprojetos elaborados em sintonia com a proposta geral e com as demandas específicas de cada área do conhecimento e das escolas campo aspirantes. Tomando como fundamento a relação teoria e prática, o Programa concebe o espaço escolar como lugar de formação e o professor da educação básica como co-formador com vistas a inserir o licenciando/bolsista na cultura escolar e profissional. Cabe ao primeiro compartilhar sua experiência com o segundo, que o acompanha no dia-a-dia da escola na condição de aprendente. Deste modo, busca-se favorecer a identificação com a docência desde os anos iniciais da graduação e, consequentemente, a permanência no curso e na futura na profissão.

Na Universidade do Estado da Bahia, o Programa teve início no ano de 2009 com 11 subprojetos, passando para 18 em 2011, subindo para 39 em 2012 e chegando a 49 entre os anos de 2014 e 2017. Neste último período, segundo Eliene Maria da Silva (2016), os subprojetos contaram com 1563 bolsistas de iniciação à docência produzindo um grande impacto nas licenciaturas desta que é a maior instituição de ensino superior da rede pública estadual baiana, que conta ainda com mais três universidades: a Universidade Estadual de Feira de Santana, a Universidade Estadual de Santa Cruz e a Universidade Estadual do Sudoeste da Bahia. Diferente destas, a UNEB se caracteriza por ser multicampi. Fundada em 1983, fez parte do 
processo de interiorização da educação superior, estando presente na capital e em 23 municípios, espalhando-se por todas as regiões do estado. Assim, a diversidade é uma das principais características da instituição que conta com 9 Licenciaturas em História, distribuídas em diferentes departamentos localizados em cidades como Salvador, Alagoinhas, Jacobina, Santo Antônio de Jesus, Caetité, Teixeira de Freitas, Itaberaba, Conceição do Coité e Eunápolis. Dos 49 subprojetos do PIBID aprovados através do edital 061/2013 da Capes, 6 destas licenciaturas foram contempladas, atingindo os seis últimos campi citados. Neles, como será visto adiante, é possível perceber uma forte relação com as demandas sociais e identitárias em curso na atualidade, incorporando temas diretamente relacionadas à diferença, sobretudo étnico-racial e de gênero, ao processo formativo dos bolsistas. Fato que justifica a escolha da relação entre formação docente e as questões identitárias do tempo presente no PIBID/História da UNEB como objeto do estudo aqui apresentado.

Entretanto, a relação entre a História e o tempo presente não corresponde a uma discussão nova. Como afirma Henry Rousso (2016), ela acompanha o trabalho do historiador desde a Grécia Antiga, passando por várias perspectivas ao longo do tempo e incorporando novos desafios e novos problemas, sobretudo no Pós-Guerra. Neste último, segundo o historiador francês, teria surgido um novo regime de historicidade, conceito este que se refere à forma como cada sociedade lida com o passado, como o pensa e como ele interfere no presente. Estudando o cenário europeu e americano, Rousso afirma que, nos últimos trinta anos, os efeitos catastróficos das duas Guerras Mundiais, sobretudo da Segunda, resultaram em uma nova relação com o passado. Os traumas do Holocausto e da Guerra em geral produziram um interesse crescente pelo tempo presente, não apenas entre os historiadores acadêmicos, mas também na TV, no cinema, na literatura, na internet, no jornalismo, na criação de arquivos e museus, nas comemorações do luto, entre outros. Colocaram em pauta a busca pela reparação e por desculpas às vítimas, transformando a história do tempo presente em um campo de ação pública.

Esta nova relação entre presente e passado também tem sido vivenciada em países da América Latina, inclusive no Brasil, no qual o peso de acontecimentos traumáticos, como as perseguições, torturas e mortes sofridas pelos opositores à ditadura militar (FICO, 2012), trouxe para o debate público a investigação sobre crimes cometidos durante o regime autoritário. A cena brasileira evidenciou ainda o encaminhamento de outras agendas, como a luta contra o racismo e contra a violência de gênero, reivindicadas pelos movimentos sociais. Lutas que 
passaram a incluir o trabalho docente nos espaços educativos, tanto nas escolas quanto nas universidades. Enfrentamentos estes que, nos estabelecimentos de ensino, encontraram legitimidade nos últimos anos, através de políticas públicas instituídas para a educação, tais como as Leis 10.639/2003 e a 11.645/2008, que determinaram a inserção da história e da cultura africana, afro-brasileira e indígena no currículo escolar, e as Diretrizes Curriculares Nacionais para a Formação Inicial em Nível Superior (2015) para as licenciaturas que estabeleceu entre os princípios para a formação de professores a educação inclusiva e o respeito às diferenças. Trata-se, portanto, de pautas que emergem das tensões sociais e identitárias que marcam a história da sociedade brasileira, cujos efeitos se propagam no tempo presente e que convocam os professores à realização de novas interpretações do passado, incluindo as histórias de sujeitos por muito tempo negligenciadas pela historiografia e pelo currículo escolar e acadêmico.

Diante disso, duas questões se colocam: como o PIBIB/História da UNEB se insere neste processo? Como os subprojetos, aprovados e executados entre os anos de 2014 e 2017, relacionam a formação inicial docente às demandas identitárias do tempo presente? Para responder a estas perguntas, inicialmente será dada ênfase ao debate travado no campo da História do Tempo Presente. Em seguida será apresentada a discussão dentro do campo do Ensino de História e suas relações com as demandas específicas em curso no Brasil nos últimos para, neste contexto, compreender os subprojetos selecionados para estudo.

\section{História do Tempo Presente e demandas sociais}

Em busca de uma definição, Cristian Delacroix (2018) indaga em que reside a singularidade da História do Tempo Presente, que a torna diferente dos demais domínios da História. Seria apenas um subperíodo da História Contemporânea ou uma outra forma de se pensar o tempo que envolveria um novo método de construção do conhecimento? Para responder a esta pergunta, o autor apresenta argumentos prós e contras a partir da perspectiva de vários teóricos. Ressalta que se trata de um problema difícil uma vez que procura apontar a autonomia do campo sem abrir mão do seu pertencimento à História. Afirma que o estatuto singular da HTP foi negado por alguns pesquisadores a exemplo de Antoine Proust, ao passo que outros, como Henri Rousso, afirmaram a sua singularidade. Apesar de essa questão parecer ultrapassada, Delacroix afirma que a retomada desse debate pode contribuir para uma reflexão mais consistente com vistas a enfrentar os desafios postos no cenário historiográfico atual. Destaca a sua filiação ao Instituto de História do Tempo Presente, criado no fim da década de 
1970, e ao Comitê Francês de História da Segunda Guerra Mundial, criado em 1951, como uma das explicações para o predomínio dos estudos sobre a Segunda Guerra Mundial, destacandose temas como o Nazismo na Alemanha e a Ocupação francesa, os quais produziram "grandes traumatismos nas identidades e nas consciências nacionais” (p.45). Fenômeno que, segundo Rousso (2016) provocou uma demanda social por memória face ao que chamou de "passados que não passam”. Dialogando com este historiador, Delacroix (2018) salienta que no processo de legitimação da HTP ocorreram tentativas de demarcação a partir das rupturas: 1827, 1945, 1989, 11 de setembro de 2001? Houve ainda debates em torno da denominação: história imediata, história do passado próximo, história do muito contemporâneo, história do tempo presente? Diante destas dificuldades, a maioria optou pelo termo História do Tempo Presente e pelo recorte temporal relativo à duração de uma vida humana, em que existem testemunhas vivas (DELACROIX, 2018). Tal definição trouxe ainda a singularidade metodológica pela possibilidade de recurso aos arquivos orais. Segundo o teórico, isto fez parte de um processo mais amplo de multiplicação de memórias em escala mundial, as quais questionaram os romances e as identidades nacionais, trazendo à cena não o herói, mas a vítima. Argumenta que essas políticas de memória estavam ligadas às políticas de reparação, provocando outros questionamentos: pode-se reparar a história? É este o papel do historiador? Estaria a História do Tempo Presente sob o risco das demandas sociais? Questões fundamentais levantadas pelo autor. Porém, antes de responde-las, é preciso sublinhar que esta relação da história com as demandas sociais não é um fenômeno exclusivo da França, podendo ser observado também em outros países, inclusive fora da Europa, onde assume dimensões particulares.

Nos EUA e Canadá, por exemplo, experts tem participado de processos relativos a direitos de minorias autóctones, discriminação racial e sexista, trazendo o tema da reparação e das afirmações identitárias, tal como expõe Olivier Dumoulin (2017). Debruçando-se sobre esse novo papel social atribuído ao historiador nas últimas décadas, ele enfatiza que, na América do Norte, o desenvolvimento de uma expertise histórica faz parte de uma configuração mais ampla denominada de História Pública, da qual participam não só os historiadores, mas também arquivistas, museólogos, cineastas, etc.; resultante não apenas da crise de empregos, mas também de uma nova maneira de apreender a relação da história com a sociedade. Se, por um lado, o autor destaca uma popularização da História, por meio da presença de historiadores na cena pública, programas de TV, produção cinematográfica, tribunais, etc., por outro, questiona a omissão, os silêncios e a autocensura dos trabalhos encomendados por clientes. 
Procedimentos esses que levaram a um não reconhecimento por parte dos acadêmicos, em menor escala no contexto norte americano e em maior escala no francês. Nesta perspectiva, discute-se até que ponto o atendimento de demandas sociais limita a liberdade do historiador. Embora relute em não se posicionar, Dumoulin (2017, p. 236) se opõe a reconhecer este novo papel e finaliza: "Depois do escritor de história, depois do professor cientista, depois do pesquisador, virá talvez o tempo do técnico da história”.

Quanto à posição de Cristian Delacroix (2018) para o contexto francês, este afirma que a relação com as demandas sociais é um dos marcadores identitários da História do Tempo Presente, posto que é produto de um novo contexto social e político, ou de um novo regime de historicidade, no qual a História passa a responder a demandas sociais do presente, mesmo entre os historiadores acadêmicos. Afirma ser a HTP não apenas uma consequência desse novo contexto, mas uma consciência dessa nova historicidade. Para ele, esta relação entre regime historiográfico e regime de historicidade, corresponde a um liame difícil de ser quebrado. Rousso (2016) teria tentado redirecionar a questão da singularidade temporal pela via do inacabado, mas sem conseguir escapar da noção do regime de historicidade presentista, preço teórico caro, haja vista o risco de confusão com o velho presentismo epistemológico de Croce. Tentando não cair nesta armadilha, Delacroix (2018) sugere outras noções contemporâneas que podem contribuir para a reflexão tais como: a ideia de "historicidades entrecruzadas e defasadas”, do presente como um "passado em deslizamento”, “passados não resolvidos”, “contemporaneidade do não contemporâneo”, entre outras. Por meio destas, seria possível romper com a ideia de um tempo linear e homogêneo, saindo das delimitações tradicionais por períodos. Essas temporalidades múltiplas são, para o teórico, constituintes de toda a História, mas são ainda mais da História do Tempo Presente pois nela há uma exacerbação da presentificação do passado. Por fim, o autor finaliza dizendo:

A HTP estaria então em um lugar privilegiado para colocar essas reflexões à prova de suas pesquisas empíricas, uma posição certamente singular, mas de modo nenhum fora do ordinário do fazer da história (DELACROIX, 2018, p. 73).

Com esta conclusão do autor, pode-se dar prosseguimento à discussão deste texto questionando o que vem a ser esse fazer ordinário da História. Trata-se do fazer historiográfico que distingue a ciência histórica de outras formas de representação do passado, entre as quais se destaca a memória, com a qual Clio sempre manteve uma relação de proximidade. Sobre a relação entre essas duas formas narrativas, Paul Ricoeur (2018), filósofo cujas concepções são 
frequentemente acessadas pelos historiadores da HTP, afirma ser a memória matriz da História, ambas se constituindo como representações do passado, porém por caminhos e processos distintos. Enquanto a primeira o faz por meio do relato da testemunha, a segunda o faz por meio da operação historiográfica. Nesta distinção, destaca-se o privilégio veritativo da memória, “o ter estado lá”, enquanto a História está sujeita a uma epistemologia. Apesar das diferenças, ambas habitam o tempo e o espaço. São construídas subjetivamente a partir do presente e do lugar social do enunciador, atravessadas, portanto, por esquecimentos e silenciamentos, dado o seu caráter seletivo. No que diz respeito à operação historiográfica, termo tomado de empréstimo a Michel de Certeau, Ricoeur distingue três etapas: a fase documental, da leitura dos documentos escritos e/ou não escritos abrigados no arquivo, espaço que se constitui como um lugar social, visto que é produto de uma seleção, do que é proibido e do que é permitido; a fase explicativa/compreensiva, na qual o documento, seja ele oral, escrito ou imagético, é problematizado em diálogo com as teorias, para produzir explicações ou respostas para as perguntas; e a fase da representação historiadora em que se dá a construção da narrativa histórica, ou seja, da escrita da história. Para o estudioso, estas não correspondem a estágios sucessivos, mas estão imbricadas. Em todas, a dimensão temporal se faz presente, posto que a História não diz respeito ao passado, mas aos homens no tempo. Reiterando Marc Bloch, Ricoeur afirma:

Essa cadeia de definições - ciência dos homens no tempo, conhecimento por rastros, testemunhos escritos e não escritos, testemunhos voluntários e involuntários - assegura o estatuto da história como ofício e do historiador como artesão (RICOEUR, 2018, p. 18).

Esta perspectiva do historiador como artesão defendida por Ricoeur se opõe à ideia do historiador como o técnico da história, termo usado por Dumoulin (2017) para se referir àqueles que se colocam a serviço de empresas e de grupos particulares. Neste último caso, o profissional da História emite uma verdade sobre determinado fato, contrariando o que é consenso atualmente sobre a impossibilidade de uma verdade absoluta sobre o passado. Ao contrário, o historiador como artesão é aquele que, por meio da operação e da crítica historiográfica, traz à tona a pluralidade de narrativas em disputas em determinada temporalidade histórica.

Se, por um lado, o historiador não pode se desvencilhar das demandas sociais que o convocam a pensar a história no tempo presente, por outro, ele não pode negligenciar as regras do ofício e sobretudo o papel da crítica neste processo. Daí porque Paul Ricoeur (2018) questiona o que ele chama de "dever de memória" e propõe no lugar deste o "trabalho de 
memória”. O fato de a História do Tempo Presente ter privilegiado o estudo dos acontecimentos traumáticos do século XX, provocados pelas duas Grandes Guerras Mundiais, evidenciou o papel das testemunhas vivas e do “dever de memória”, este entendido como uma obrigação, uma forma de reparação e de fazer justiça às vítimas. Entretanto, é papel do historiador atender ao “dever de memória”? Para Ricoeur, não. Sobre esta posição, Delacroix (2018) assevera que embora se oponha ao dever de memória, propondo a sua substituição pelo "trabalho de memória”, o filósofo não separa a dimensão epistemológica da questão ética. Articulação esta que se coloca como solução para o problema ao levar à “justa memória”, em que o historiador não abre mão da crítica historiográfica, evitando os abusos da ideologização da memória, tanto pela via da lembrança quanto pela via do esquecimento.

Para finalizar, resta ainda questionar que tempo é esse sobre o qual se debruça o historiador do tempo presente no seu fazer historiográfico. Uma das principais críticas dirigidas à HTP é o fato desta lidar com acontecimentos ainda não concluídos e sobre os quais não seria possível ainda fazer uma análise, visão esta que parte de uma perspectiva linear da História, que marcou fortemente o historicismo no século XIX. Em contraposição a este pensamento, outras concepções surgiram ao longo do século XX, a exemplo da crítica construída pelo movimento dos Annales ao acontecimento visto como individual, político e cronológico. O maior representante dessa recusa foi Fernand Braudel. Segundo Jacques Revel (2009), em diálogo com as ciências sociais, Braudel explicitou a coexistência de diversas durações temporais: a curta, a média e a longa duração. Esta última sendo privilegiada em suas pesquisas que se centravam no estudo nas estruturas sociais, tomadas como quase imóveis, em detrimento do acontecimento, enquanto ruptura. Este sendo retomado pela historiografia, conforme Revel, nas décadas de 1980 e 1990, por meio da integração do acontecimento às estruturas através dos trabalhos de Georges Duby, Emamanuel Le Roy Ladurie, Natalie Zemon Davis, Robert Darnton, entre outros. Todavia, em que pesem as mudanças assinaladas, segundo o teórico, esses historiadores ainda estavam presos às hierarquias das durações. Coube a Reinhart Koselleck se contrapor a esta perspectiva e apontar a relação não hierárquica entre o acontecimento e a estrutura, salientando a multiplicidade de temporalidades. Koselleck (Apud, REVEL, 2009) defende que o regime de historicidade é definido pela tensão entre o um espaço de experiência e o horizonte de expectativa.

Percebe-se melhor o caráter irredutível do acontecimento nesta perspectiva. Ele não revela somente uma restrição à enunciação, mas também uma exigência de tipo 
cognitivo já que é constituído por um nó de diversas temporalidades atualizadas num dado momento. Mas é neste emaranhado de durações que se ancora a dinâmica histórica, aquela que vivem os atores que se movem em vários tempos ao mesmo tempo e aquela, não linear que cabe aos historiadores dar conta. (REVEL, 2009, p. 93).

Rompendo com a dualidade das concepções linear e cíclica, Koselleck (2014, p. 20) defende a noção de estratos tempo para se referir às diversas camadas de temporalidades que coexistem simultaneamente e que "remetem uns aos outros, mas que não dependem completamente uns dos outros”. Deste modo, a história não seria construída apenas por singularidades, mas também por estruturas de repetição, as quais também mudam. Assim, o teórico afirma que:

o proveito de uma teoria dos estratos do tempo consiste em sua capacidade de medir diferentes velocidades, acelerações, atrasos, tornando visíveis os diferentes modos de mudança, que exibem grande complexidade temporal” (KOSELLECK, 2014, p. 22).

A teoria de Koselleck tem sido salutar aos historiadores da HTP para a compreensão das relações entre as diversas temporalidades, não como passagem de um tempo a outro, mas como coexistências e/ou entrecruzamentos de tempos diversos em uma mesma época. Nesse sentido, o presente se configura como o tempo do inacabado, do incerto e do indeterminado. Nele, o passado se constitui como memória e o futuro como expectativa. Uma vez que os acontecimentos não apresentam os mesmos ritmos e durações, os diversos tempos coexistem e se interpenetram numa mesma temporalidade.

Todas essas questões até aqui apresentadas repercutem não apenas sobre a produção historiográfica, mas também sobre o ensino de história e, consequentemente, sobre a formação de professores/historiadores. Assim, de que maneira, as questões até aqui apresentadas se traduzem no campo da formação docente em História? Como os subprojetos do PIBID/UNEB se inserem neste processo e relacionam o ensino de História às demandas identitárias, sobretudo de raça e de gênero, ao processo de iniciação à docência? Aderem à uma política reparatória, seguindo a lógica do “dever de memória” ou do “trabalho de memória”?

\section{Formação docente em História e demandas do tempo presente}

A respeito das relações entre as questões do tempo presente e o ensino de história, são salutares as reflexões levantadas pela professora Cristiani Bereta da Silva (2016) ao analisar, a partir da sua atuação na disciplina Estágio Supervisionado e como coordenadora de área do subprojeto do PIBID na Universidade do Estado de Santa Catarina, os desafios enfrentados por 
ela e por seus alunos no exercício da formação inicial em História. Entre os desafios que a autora destaca, estão a orientação temporal, o dever de memória e os usos do passado. Ao refletir sobre o primeiro, dialoga com Jörn Rüsen, historiador alemão para quem a construção de um sentido histórico não se limita aos historiadores, mas faz parte da vida de todo ser humano e corresponde ao que o teórico compreende por "consciência histórica”: a necessidade de se orientar no presente e projetar o futuro a partir do passado. Assim, este último não pode estar ausente das aulas de História. Para a estudiosa, esta tem sido uma das maiores dificuldades, visto que, muitas vezes, o passado se dispersa quando as questões do tempo presente são introduzidas nas aulas. Para ela, é necessário que os temas da atualidade sejam objeto de discussão, mas sem prescindir do passado e da relação entre ambas as temporalidades. Ao se debruçar sobre o segundo desafio, que diz respeito ao dever de memória, destaca como, no Brasil atual, diversas mudanças têm sido introduzidas no ensino de História, resultantes de reivindicações dos movimentos sociais de negros, indígenas, mulheres, entre outros, provocando revisões e alterando conteúdos, manuais, metodologias, as finalidades do ensino e a formação docente. Neste contexto, a autora cita as diretrizes nacionais para o ensino na educação básica, nas quais figuram como um dos objetivos a formação da cidadania, estabelecendo relações entre identidades individuais e coletivas; e as Leis 10.639/2003 e 11.645/2008, que determinam a obrigatoriedade do ensino da história e cultura africana, afrobrasileira e indígena. Frente a essas conquistas, segundo suas observações, alguns licenciandos tem atuado como mediadores dessas políticas afirmativas, aderindo a uma concepção compensatória e de dever de justiça em sua prática docente. Sem contrariar a inclusão dessas temáticas, que se assentam na pluralidade de culturas e de identidades e no combate às desigualdades, Silva defende que "a relação entre história e cidadania, história e justiça social, deve se dar no nível da compreensão dos processos históricos” (SILVA, 2016, p. 128), que tornariam possível a elaboração de argumentos para fundamentar ações assentadas na justiça, no respeito e na igualdade na diferença. O terceiro e último desafio colocado se refere aos usos do passado e à história de grande circulação. A este respeito, ela chama a atenção para a história que tem sido produzida por meio do cinema, da literatura, da música, etc., cujos processos de elaboração são diferentes daqueles usados pelos historiadores e que têm sido crescentemente utilizados nas aulas para abordar questões do tempo presente, vinculando-se ao dever de memória ou ao que o pensador britânico Oakeshott (Apud, SILVA, 2016) chamou de passado prático. Este entendido como o uso do passado para justificar e atender a projetos políticos do 
presente. Para não cair nessas armadilhas, a autora destaca a importância de o professor dialogar de forma cuidadosa com os diversos sentidos atribuídos à história, a saber: a história como forma pública de conhecimento, divulgada pelas mídias e instituições públicas; e a história como forma de pensamento e como experiência de orientação temporal. Uma vez que estas dimensões se fazem presentes na história escolar, é imprescindível o diálogo, porém sem confundi-las. Ressalta também a importância de se distinguir esses sentidos, bem como a história, enquanto vivido, e a História como campo disciplinar: “é necessário investir na compreensão de que o passado persiste no presente. Do mesmo modo que é absolutamente necessário que não haja confusão entre os tipos de história e de passados que marcam presença na sala de aula” (SILVA, 2016, p. 134).

Significativas também são as questões levantadas por Ana Maria Monteiro (2015). A partir de referenciais teóricos do campo da educação e da historiografia, Monteiro ressalta que os professores ensinam a partir de demandas presentes na sociedade e nas diretrizes curriculares vigentes, articulando cultura e saberes científicos. Para ela, a temporalidade, e dentro dela o tempo presente, é tão importante para o conhecimento histórico escolar quanto o é para o conhecimento acadêmico. Defende a articulação entre tempo e narrativa, assim como entre passado e presente, entre conhecimento e "realidade" do aluno, como fundamental para a produção de saberes significativos no ensino. Partindo dessa premissa, a aula se configura, para Monteiro, como espaço de experiência e horizonte de expectativa, seja por meio de aprovação em vestibulares ou por meio da formação de cidadãos críticos.

A relação entre as diversas temporalidades também é objeto de reflexão do pesquisador espanhol Joan Pagès e da pesquisadora argentina Maria Paula González (2014). Dialogando com teóricos da Europa e da América Latina, analisam a relação entre memória e História, tomando os dois como campos distintos, mas que se aproximam por se constituírem como narrativas sobre passado construídas no presente e, portanto, dotada de subjetividades. Na escola ambas se encontram, segundo Pagès e González, atuando na produção de identidades. Afirmam que, tanto nos países europeus quanto nos latino-americanos, contribuíram para a construção de um olhar homogeneizador e pacífico sobre o passado, apagando as diferenças e os conflitos étnicos e sociais. Partindo desta constatação, defendem que no presente, frente aos “passados socialmente vivos” ou traumáticos, a prática docente escolar não deve simplesmente substituir a narrativa dos algozes pelas das vítimas. Longe disso, deve se orientar no sentido de 
evitar os “abusos da memória” e, por meio da problematização e da crítica, questionar as versões oficiais ainda hegemônicas.

Com base nestas concepções, é fundamental compreender como a relação com as demandas sociais, com “os passados que não passam” ou "socialmente vivos”, presentes em temas traumáticos como o racismo e desigualdades de gênero, têm sido abordados no campo da formação docente. Aqui, a análise será feita a partir das propostas realizadas no PIBID/UNEB. Porém não se trata de generalizar, tomando um universo específico como modelo, mas de, a partir dele, refletir sobre o tema.

É preciso ressaltar que o próprio PIBID, enquanto programa de iniciação à docência, se constitui como uma demanda do tempo presente. Tempo este que traz entre seus problemas a desvalorização do magistério ocorrida desde as últimas décadas do século XX. Baixos salários, salas de aulas superlotadas, indisciplina, falta de estrutura escolar, entre outros, tem tornado o magistério uma profissão pouco atraente para os jovens. Soma-se a isso, o fato de que os cursos de licenciatura, historicamente, investiram a maior parte da sua carga-horária na formação de pesquisadores, em detrimento da formação docente. Neste cenário, em 2007, dentro das ações do Plano Nacional de Desenvolvimento da Educação, foi criado o PIBID, sendo regulamentado em 2009, como uma política pública voltada para a valorização da docência. Segundo a instrução normativa de 2013, figuram entre os seus objetivos:

II - contribuir para a valorização do magistério;

III - elevar a qualidade da formação inicial de professores nos cursos de licenciatura, promovendo a integração entre educação superior e educação básica;

IV - inserir os licenciandos no cotidiano de escolas da rede pública de educação, proporcionando-lhes oportunidades de criação e participação em experiências metodológicas, tecnológicas e práticas docentes de caráter inovador e interdisciplinar que busquem a superação de problemas identificados no processo de ensino aprendizagem;

V - incentivar escolas públicas de educação básica, mobilizando seus professores como co-formadores dos futuros docentes e tornando-as protagonistas nos processos de formação inicial para o magistério;

VI - contribuir para a articulação entre teoria e prática necessárias à formação dos docentes, elevando a qualidade das ações acadêmicas nos cursos de licenciatura; VII - contribuir para que os estudantes de licenciatura se insiram na cultura escolar do magistério, por meio da apropriação e da reflexão sobre instrumentos, saberes e peculiaridades do trabalho docente.

(Portaria nº 096 publicada no Diário Oficial da União em 18 de Julho de 2013)

Ao incentivo à formação docente, assim como à permanência do estudante nas licenciaturas, soma-se a articulação entre universidades e escolas como forma de fortalecer e 
melhorar a qualidade da educação básica. A princípio vinculado às Instituições de Ensino Superior Federais, priorizando-se os cursos da área de Exatas nas Universidades e o Ensino Médio na Educação Básica, posteriormente ampliou a sua abrangência passando a incluir as universidades estaduais, entre outras. Manteve os objetivos anteriores, acrescentando-se mais um:

proporcionar aos futuros professores participação em experiências metodológicas, tecnológicas e práticas docentes de caráter inovador e interdisciplinar e que busquem a superação de problemas identificados no processo de ensino-aprendizagem, levando em consideração o desempenho da escola em avaliações nacionais, como Provinha Brasil, Prova Brasil, SAEB, ENEM, entre outras; (Inciso V do artigo $1^{\circ}$ da resolução da Capes publicada no Diário Oficial da União do dia 16 de Setembro de 2009).

Além de destacar o papel da prática no enfrentamento dos problemas escolares como fundamental à formação docente, o documento determina como critério para seleção das escolas parceiras o baixo desempenho destas nas avaliações nacionais. Através de convênio entre escolas e universidades, as medidas visavam melhorar a qualidade dos cursos de formação de professores e do ensino básico. Para tanto, foi essencial a indução e fomento da Capes, Coordenação de Aperfeiçoamento Profissional, que, apesar de atuar junto ao MEC, teve sua atuação por muito tempo restrita ao financiamento de programas voltados para o desenvolvimento científico e tecnológico e à Pós-Graduação. Através da Lei $\mathrm{n}^{\circ}$ 11.502, de 11 de Julho de 2007, o governo incluiu entre as atribuições do órgão a elaboração de políticas para a formação inicial e continuada de professores da educação básica. Uma mudança histórica que ao longo dos últimos dez anos teve grande contribuição para o sucesso do PIBID, o qual possibilitou, de acordo com Bernadete Gatti e outras (2014): a articulação efetiva entre teoria e prática, entre universidades e escolas; a elevação da autoestima de alunos das licenciaturas e professores das escolas; uma maior preparação para o Estágio Supervisionado e o desenvolvimento do pensamento crítico sobre os currículos acadêmicos; e a crescente produção de materiais didáticos e trabalhos científicos sobre a prática escolar, entre outros.

A Universidade do Estado da Bahia foi uma das pioneiras no Programa, tendo concorrido ao edital de 2009, cuja convocação se estendeu a todas as instituições de ensino superior públicas do país. Todas os objetivos propostos nos documentos oficiais citados acima foram contemplados nos subprojetos das licenciaturas em História da UNEB, uma vez que as propostas estavam submetidas ao projeto guarda-chuva da instituição para o quadriênio 20142017, seguindo a instrução normativa de vigência nacional. Eliene Maria da Silva (2016, p. 
133), analisando as experiencias realizadas na instituição baiana até o ano de 2016, afirma que o PIBID possibilitou aos licenciandos/bolsistas o desenvolvimento de uma experiencia préprofissional, favorecendo a “transição da discência para a docência” por meio de “uma iniciação compartilhada”. Ao serem inseridos na profissão, participando de todas atividades realizadas na escola pelo professor, e sob a supervisão destes, os iniciantes vão, progressivamente, se identificando com a profissão. As análises de Silva valem para todas as licenciaturas, porém, no caso dos cursos de formação de professores de História, foco deste artigo, as propostas de intervenção para esta área formativa apresentam algumas especificidades, indo além do que propõe o Programa, ao incorporar demandas próprias deste campo disciplinar e também do tempo presente. As Licenciaturas em História, apesar de se constituírem como cursos de formação de professores, por muito tempo se limitavam a formar historiadores, destinando pouco espaço para a discussão de temas relativos à prática de ensino e à aprendizagem histórica, que geralmente ficavam sob a responsabilidade da área de metodologia e/ou de estágio supervisionado. Tal percepção, que dicotomiza ensino e pesquisa, e que tem sido profundamente criticada por professores e pesquisadores do campo nas últimas décadas, vem sendo também desconstruída no PIBID, levando os licenciandos a questionarem o currículo acadêmico.

Analisando os subprojetos da UNEB aprovados pelo edital de 2013 e que estiveram em vigência entre 2014 e 2017, pode-se notar em todos uma preocupação com a formação de professores/historiadores. São eles: A Formação Inicial do Professor de História e sua Atuação na Escola Básica: O Oficio do Historiador na Docência (Campus VI - Caetité); A História e o Social: A Comunidade e os Espaços da Cidade como Integrantes do Processo de EnsinoAprendizagem (Campus X - Teixeira de Freitas); e A práxis Colaborativa na Formação do Professor de História: Compartilhando Diálogos e Resinificando Práticas entre a Universidade e a Educação Escolar (Campus XVIII - Eunápolis); Tecendo Histórias e Formando Professores: Memórias, Contos e Encantos nas Expressões Socioculturais, e Histórias no Cotidiano dos Afro-Brasileiros, (Campus V - Santo Antônio de Jesus); A Memória Regional vai à Escola: Tradição, Cultural e Oralidade em Diálogos com a Lei 11.645/08 em Itaberaba (Campus XIII - Itaberaba); O Diferente na Escola - Formação Docente, Ensino e Abordagem do Conteúdo Multicultural no Ensino de História (Campus XIV - Conceição do Coité). Em todos, a escola e a sala de aula são assumidas como lugares de produção de conhecimento histórico. No entanto, nos três últimos, nota-se que a formação do 
professor historiador é concebida de modo inseparável da incorporação de temas e da produção de sensibilidades sobre os passados “socialmente vivos”. Entrecruzam temporalidades diversas ao dar visibilidade a sujeitos e narrativas historicamente silenciadas, como as das populações africanas, afro-brasileiras, indígenas e LGBTs, com vistas a combater discriminações raciais, de gênero e homofobia. Colocam-se em sintonia com o Plano Nacional de Educação em Direitos Humanos (2007, p. 33) o qual estabelece que, na educação básica, deve-se “ [...] fomentar a inclusão, no currículo escolar, das temáticas relativas a gênero, identidade de gênero, raça e etnia, religião, orientação sexual, pessoas com deficiências, entre outros, bem como todas as formas de discriminação e violações de direitos [...]”. O Plano coloca ainda, para as instituições de ensino superior,

[..] a nobre tarefa de formação de cidadãos(ãs) hábeis para participar de uma sociedade livre, democrática e tolerante com as diferenças étnico-racial, religiosa, cultural, territorial, físico-individual, geracional, de gênero, de orientação sexual, de opção política, de nacionalidade, dentre outras (p. 38).

Os subprojetos se afinam também com as Lei 10.639/2003, que tornou obrigatório o ensino da história e da cultura africana e afro-brasileira nas escolas, e com a Lei 11.645/2008, que estende esta obrigatoriedade à inserção da história e cultura indígenas. Estão igualmente em consonância com as Diretrizes Curriculares Nacionais Para a Formação Inicial em Nível Superior (2015), segundo a qual os cursos de licenciaturas devem se voltar “à consolidação da educação inclusiva através do respeito às diferenças, reconhecendo e valorizando a diversidade étnico-racial, de gênero, sexual, religiosa, de faixa geracional, entre outras” (capítulo 2, inciso $5^{\circ}$, inciso VIII). As proposições do PIBID/História da UNEB se conectam, portanto, com as demandas sociais e identitárias do tempo presente, cuja incorporação nesses documentos legais citados são conquistas dos movimentos feministas, negro, indígena e LGBT, entre outros. Indicam, deste modo, a construção de experiencias formativas voltadas para inserção, no espaço escolar, do debate sobre a produção da diferença e das desigualdades, como ser visto nos trechos abaixo:

Ao longo da sua execução, o projeto vem buscando construir subsídios epistemológicos para os participantes: bolsistas e estudantes/docentes, do referido Colégio, a partir da Lei 10.639/2003, como também vem contribuindo para a inserção dos graduandos em história no espaço escolar, lócus de atuação dos futuros profissionais do ensino de história, tanto da história da África e cultura afro-brasileira, bem como seus possíveis desdobramentos na história local e regional. Neste contexto confirma-se a primazia em 
manter e aprofundar o debate entre os diversos saberes - sejam eles acadêmicos e/ou populares - na perspectiva de (in) formar as comunidades acadêmicas e civis sobre a importância da Cultura Afro-Brasileira, para construirmos estratégias políticas e pedagógicas com o intuito de compreender e direcionar as relações étnico-raciais no sentido do respeito e correção de posturas e atitudes discriminatórias e racistas. (Subprojeto Tecendo Histórias e formando professores: memórias, contos e encantos nas expressões socioculturais e históricas no cotidiano dos afro-brasileiros, 2013, p. 3).

A importância da diversidade foi trazida à tona através da Lei 11.645/08, estabelecendo a obrigatoriedade da inserção da História e Cultura afro-brasileira e indígena no currículo da Educação Básica, tendo exatamente a componente História como um dos carro-chefe para este fim. Nas escolas públicas de Itaberaba há uma sólida maioria de alunos e professores afrodescendentes ou índio-descendentes; a região tem forte memória indígena, do povo Payayá. Os estudantes sertanejos, são afro-índios. Nossos Licenciandos em História há muito vêm percebendo isso e produzindo bons trabalhos sobre História Regional e Local, cultura e memória afro-indígena. Estes saberes precisam chegar à educação básica não só para que se cumpra a Lei 11.645/08 de maneira efetiva, mas principalmente para que se faça uma revolução na qualidade da educação básica e na forma como os alunos se veem enquanto sujeitos históricos (Subprojeto A memória regional vai à escola: tradição, cultura e oralidade em diálogos com a Lei 11.645/08 em Itaberaba, 2013, p. 4).

Nesta unidade de ensino, nossos bolsistas refletiram sobre sua própria formação de modo a perceber as dificuldades do exercício de sua profissão sem um acesso a teorias das relações raciais, de gênero e sexualidade. Uma vez em contato com o público escolar, os bolsistas tiveram a oportunidade de reconhecer que adolescentes e jovens, negros e negras, héteros, homos ou bissexuais, da zona urbana ou rural, têm vivenciado um ambiente escolar inibidor e desfavorável ao seu sucesso, ao desenvolvimento pleno de suas potencialidades, tornando a experiência de sua formação identitária uma trajetória marcada pela violência, discriminação e preconceito (Subprojeto O Diferente na Escola - Formação Docente, Ensino e Abordagem do Conteúdo Multicultural no Ensino de História, 2013, p. 5).

Ao incorporar temas ligados às relações étnico-raciais, de gênero e sexualidade, os textos citados problematizam e denunciam o currículo acadêmico, uma vez que este, apesar dos avanços, ainda não teria conseguido dar conta dessas questões de modo satisfatório, o que justificaria as propostas. Outro argumento é o fato de a escola ser um espaço marcado pela diversidade, ao mesmo tempo em que não a incorpora nas atividades curriculares, impondo como padrão o modelo masculino, branco e hétero-patriarcal como sujeito histórico. Deste modo, ao incluírem a história das mulheres, das populações africanas, afro-brasileiras, indígenas e LGBTTs, entre outras, as propostas de intervenção reconhecem o direito desses grupos de terem suas narrativas históricas contempladas, contribuindo para romper com o eurocentrismo que ainda permeia o currículo acadêmico e o escolar. Tal inserção, se coloca como fundamental para tornar as aulas significativas para os estudantes, colaborando para o 
combate à todas as formas de preconceito e discriminação. Com base no exposto, é possível concluir que relacionam passado e presente, trazendo à tona experiências traumáticas como o racismo, violência de gênero e LGBTfobia como construções históricas que se atualizam e persistem no presente. Ao fazerem isto, concebem o passado não como algo frio e distante, mas como coexistindo no presente, já que é “socialmente vivo”. A formação inicial docente em História, assume uma dimensão política na medida em que pretende atender demandas sociais e identitárias presentes nas ações afirmativas, de inclusão e reparação reivindicadas pelos movimentos sociais e legitimadas pelas políticas públicas para a educação nos últimos anos. No entanto, não o fazem na perspectiva do “dever de memória”, visto que não propõem a substituição de uma narrativa por outra, mas a problematização, a contraposição de versões e a inclusão daquelas historicamente silenciadas pelo sistema global de poder capitalista. Este, segundo Lugones e outras (2013), constituindo-se como um modelo individualista e violento, impôs a colonialidade do saber, de raça e de gênero, ao tomar o conhecimento eurocêntrico, branco e hétero como universalmente válido, negando aos homens e mulheres indígenas e afrodiaspóricas o direito à fala e à existência. Assim, ao propor a inclusão das narrativas históricas desses sujeitos no campo da formação, os subprojetos do PIBID/História da UNEB contribuem para formar o professor/historiador como artesão, induzindo à incorporação de versões historiográficas plurais nas aulas de História. Com isto, almejam a “justa memória”, por partilharem o entendimento de que a construção de uma educação democrática só é possível através do combate às desigualdades e do respeito aos direitos humanos.

\section{Considerações finais}

Este trabalho apresentou algumas reflexões sobre uma pesquisa que ainda se encontra em andamento. Suas análises, portanto, ainda são parciais. Porém, permitem afirmar que uma parte significativa dos subprojetos PIBID/História da UNEB executados entre 2014 e 2017, inserem-se nas disputas de narrativas para dar visibilidade às narrativas silenciadas, tais como a dos negros, mulheres e LGBTTs. Articulam-se às demandas sociais e identitárias que tem afetado o trabalho de historiadores e de professores no tempo presente. Colocam-se em sintonia com as políticas públicas para a educação vigentes no Brasil nos últimos anos. Ao tocar em temas que dizem respeito aos "passados socialmente vivos", indicam a coexistência de temporalidades diversas: um presente marcado por demandas identitárias de grupos sociais que exigem reparação frente à experiências históricas traumáticas, a exemplo do racismo, violência 
de gênero e LGBTfobia, produzidos historicamente e que se constituem como feridas ainda abertas, questões não resolvidas tanto no passado quanto no presente. Ao fazê-lo, expressam uma implicação ética e política, entrecruzando presente e passado, numa relação fundamental para a construção de um trabalho voltado para o exercício dos direitos humanos, comprometido com a construção de uma sociedade democrática e socialmente justa.

\section{Fontes}

DIRETRIZES CURRICULARES NACIONAIS PARA A FORMAÇÃO INICIAL EM NÍVEL SUPERIOR (cursos de licenciatura, cursos de formação pedagógica para graduados e cursos de segunda licenciatura) e para a formação continuada, publicado em $1^{0}$ de Julho de 2015. Disponível

em: http://portal.mec.gov.br/index.php?option=com_docman\&view=download\&alias=70431res-cne-cp-002-03072015-pdf\&category_slug=agosto-2017-pdf\&Itemid=30192. Acesso em 17/09/2019.

LEI $\mathrm{N}^{\mathrm{o}}$ 11.502, de 11 de Julho de 2007. Disponível em: http://www.planalto.gov.br/ccivil_03/_Ato2007-2010/2007/Lei/L11502.htm. Acesso em $11 / 02 / 2019$.

PLANO NACIONAL DE DESENVOLVIMENTO DA EDUCAÇÃO, 2007. Disponível em: http://portal.mec.gov.br/arquivos/livro/livro.pdf. Acesso em 11/02/2019.

PLANO NACIONAL DE EDUCAÇÃO EM DIREITOS HUMANOS. Brasília: Secretaria Especial dos Direitos Humanos, Ministério da Educação, Ministério da Justiça, UNESCO, 2007. Disponível em: http://portal.mec.gov.br/docman/2191-plano-nacional-pdf/file. Acesso em 08/11/2019.

PROGRAMA INSTITUCIONAL DE BOLSA DE INICIAÇÃO À DOCÊNCIA. Edital N ${ }^{\circ}$ 061/2013. Disponível em: https://www.capes.gov.br/images/stories/download/editais/Edital_061_2013_PIBID.pdf. Acesso em 08/11/2019.

PROGRAMA INSTITUCIONAL DE BOLSAS DE INICIAÇÃO À DOCÊNCIA. Portaria nº 096/2013.

Disponível

em: https://www.capes.gov.br/images/stories/download/legislacao/Portaria_096_18jul13_Apr ovaRegulamentoPIBID.pdf. Acesso em 08/11/2019.

PROGRAMA INSTITUCIONAL DE BOLSAS DE INCIAÇÃO À DOCÊNCIA. Resolução Capes, 16 de $\quad$ Setembro, de $2009 . \quad$ Disponível em: http://www.capes.gov.br/images/stories/download/bolsas/PortariaNormativa122_PIBID.p df. Acesso em 11/02/2019. 
SUBPROJETOS PIBID/UNEB. Disponível em: http://www.uneb.br/pibid/subprojetos_pibidcapes/. Acesso em 11/02/2019.

\section{Referências bibliográficas}

DELACROIX, Christian. A história do tempo presente, uma história (realmente) como as outras? Tempo e Argumento, Florianópolis, v. 10, n. 23, p. 39 - 79, jan./mar. 2018.

DUMOULIN, Olivier. O papel social do historiador: da cátedra ao tribunal. São Paulo: Autêntica, 2017.

FICO, Carlos. História do tempo presente, eventos traumáticos e documentos sensíveis: o caso brasileiro. In.: Varia História, Belo Horizonte, v. 28, n. 47, p. 43-59, jan./jun. 2012. Disponível em: www.scielo.br/pdf/vh/v28n47/03.pdf. Acesso em 29/03/2018.

GATTI, Bernadete A.; ANDRÉ, Marli E. D. A.; Nelson A. S. Gimenes; FERRAGUT. Laurizete. Um estudo avaliativo do Programa Institucional de Bolsa de Iniciação à Docência (Pibid). São Paulo: FCC/SEP, 2014. Disponível em:

https://www.capes.gov.br/images/stories/.../24112014-pibid-arquivoAnexado.pdf

Acesso em 25/01/2019.

GONZÁLEZ, Maria Paula e Pagès, Joan. Historia, memoria y enseñanza de la historia: conceptos, debates y perspectivas europeas e latino-americanas. In.: Historia y memoria, $\mathrm{N}^{\circ} .9$.

Año 2014, pp. 275-311. Disponível em: http://www.scielo.org.co/scielo.php?script=sci_arttext\&pid=S2027-51372014000200010.

Acesso em 22/02/2014.

KOSELLECK, Reinhart. Estratos do tempo: estudos sobre história. Rio de Janeiro: Contratempo, 2014.

MONTEIRO, Ana Maria. Aulas de História: questões do/no tempo presente.

Educar em Revista, Curitiba, Brasil, n. 58, p. 165-182, out./dez. 2015. Disponível em: http://www.scielo.br/pdf/er/n58/1984-0411-er-58-00165.pdf. Acesso em 24/02/2019.

REVEL, Jacques. Retornar ao acontecimento - Um itinerário historiográfico. In.: GONDRA, José; e outros. Proposições: ensaios de História e Historiografia. Rio de Janeiro: EDUERJ, 2009.

RICOEUR, Paul. A memória, a história, o esquecimento. Campinas: Editora da Unicamp, 2018. ROUSSO, Henry. A última catástrofe: a história, o presente, o contemporâneo. Trad. Fernando Coelho e Fabrício Coelho. Rio de Janeiro: FGV, 2016.

SILVA, Cristiani Bereta da. Que memória? Que história? Usos do passado e o ensino de História a partir do presente.In.: GONÇALVES, Janice (Org.). História do tempo presente: oralidade, memória e mídia. Itají, SC: Casa Aberta, 2016.

SILVA, Eliene Maria da. A iniciação à docência no processo da aprendizagem docente: um estudo no Programa Institucional de Bolsa de Iniciação à Docência Pibid / Capes na Universidade do Estado da Bahia - UNEB. Programa de Pós-graduação em Educação, UFBA, 2017. Disponível em: https://catalogodeteses.capes.gov.br. Acesso em 06/02/2019. 